\title{
INFORMASI GIZI, JENIS KELAMIN, RIWAYAT PENYAKIT KELUARGA, DAN SINDROM METABOLIK DI YOGYAKARTA
}

\author{
(Nutrition Information, Sex, Family Disease History And Syndrome \\ Metabolic In Yogyakarta)
}

\author{
Agil Dhiemitra Aulia Dewi dan Silvi Lailatul Mahfida
}

\begin{abstract}
Program Studi Gizi, Fakultas Ilmu Kesehatan, Universitas Aisyiyah Yogyakarta Jalan Siliwangi (Ring Road Barat) No. 63, Mlangi, Nogotirto, Gamping, Sleman, D.I. Yogyakarta 55292

Email: aagildhiemitra@unisayogya.ac.id, bsilvilailatul@unisayogya.ac.id
\end{abstract}

\begin{abstract}
Metabolic syndrome (MetS) related to the increasing risks of cardiovascular and diabetes mellitus type 2 and also death at young age. Nutrition, family disease history, and sex often related to MetS prevalence. This study aims to analyze variables which related to metabolic syndrome in Yogyakarta. This case control study was carried out in August-September 2018. The sample were 33 cases and 47 controls who were selected by quota sampling in Province of Yogyakarta Special Region. The data was taken from primary health centers of in each selected sub districts from Yogyakarta District and Bantul District. Sex and history of family with degenerative diseases were related to MetS $(p<0,05)$. Women have 3,77 times higher risk to experience MetS compared to men. Individual from family with history of degenerative diseases have 3,75 times higher risk to experience metabolic syndrome than individuals from family without history of degenerative disease. Sex and family disease history are related to MetS. Women and individuals from family with history of degenerative disease have a higher risk to experience MetS.
\end{abstract}

Keywords : Metabolic Syndrome, Sex, Family Disease History

\begin{abstract}
ABSTRAK
Sindrom metabolik berhubungan dengan meningkatnya risiko penyakit kardiovaskular, diabetes melitus tipe 2 dan kematian muda. Informasi mengenai gizi, riwayat penyakit keluarga, dan jenis kelamin sering dikaitkan dengan kejadian sindrom metabolik. Penelitian ini bertujuan untuk mengetahui variabelvariabel yang berhubungan dengan sindrom metabolik di Yogyakarta. Penelitian case cantrol dilaksanakan pada bulan Agustus - September 2018 di Provinsi Daerah Istimewa Yogyakarta. Besar sample adalah 33 kasus dan 47 kontrol, yang dipilih dengan metode quota sampling . Data di ambil dari Puskesmas di setiap Kecamatan terpilih di Kabupaten Bantul dan Kotamadya Yogyakarta. Jenis kelamin dan riwayat adanya keluarga yang menderita penyakit degeneratif berhubungan signifikan dengan sindrom metabolik $(\mathrm{p}<0,05)$. Wanita memiliki risiko 3,77 lebih tinggi untuk mengalami sindrom metabolik dibanding laki-laki. Individu dari kelurga dengan riwayat penyakit degeneratif memiliki risiko 3,75 kali lebih tinggi untuk mengalami sindrom metabolik. Jenis kelamin dan riwayat keluarga menderita penyakit degeneratif berhubungan dengan kejadian sindrom metabolik. Wanita dan individu dari keluarga dengan riwayat menderita penyakit degeneratif memiliki risiko lebih tinggi mengalami sindrom metabolik.
\end{abstract}

Kata kunci: Sindrom Metabolik, Jenis Kelamin, Riwayat Penyakit Keluarga 
PENDAHULUAN

\begin{abstract}
Sindrom metabolik (Metabolic Syndrome/MetS)

merupakan

sekumpulan gejala dari ketidaknormalan

metabolisme dalam tubuh, antara lain

resistensi insulin, hiperglikemia, obesitas, dislipidemia aterogenik (kadar trigliserida > $150 \mathrm{mg} / \mathrm{dL}$; HDL rendah, LDL tinggi), dan hipertensi (Huang, 2009) Hiperlipidemia sebagai salah satu komponen kriteria MetS merupakan salah satu faktor risiko penyakit kardiovaskuler dan salah satunya dapat dilihat dari kadar trigliserida, HDL,
\end{abstract} LDL (Parikh and Mohan, 2012) (Nelson, 2014). Ada beberapa definisi MetS yang dibuat oleh beberapa organisasi di dunia, diantaranya adalah World Health Organization (WHO), Adult Treatment Panel III (ATP III), International Diabetes Federation (IDF). Definisi tersebut berbeda dalam hal cut off point kriteria MetS atau pada komponen kriteria. Dari ketiga definisi tersebut, definisi MetS dari WHO dan ATP III yang tampak berkaitan dalam skrining risiko penyakit kardiovaskuler dibandingkan dengan IDF (Hadaegh $e t$ al., 2009). Menurut ATP III, seseorang dikategorikan mengalami sindrom metabolik jika memenuhi 3 dari 5 kriteria komponen sindrom metabolik yaitu Waist Circumference $\geq 102 \mathrm{~cm}$ pada laki-laki atau $\geq 88 \mathrm{~cm}$ pada perempuan; Trigliserida $\geq 150 \mathrm{mg} / \mathrm{dl}$ dan atau HDL-C $<40 \mathrm{mg} / \mathrm{dl}$ pada lakilaki atau $<50 \mathrm{mg} / \mathrm{dl}$ pada perempuan; $\geq 130 / 85 \mathrm{~mm} \mathrm{Hg}$; kadar glukosa darah puasa > $110 \mathrm{mg} / \mathrm{dl}$ (Grundy et al., 2004).

Di Amerika Serikat pada taun 1988 - 2012, angka kejadian MetS semakin meningkat pada setiap kelompok sosiodemografi, dilihat dari data National Health and Nutrition Examination Survey (NHES) (Moore, Chaudary and Aldnyemiju, 2017). Di Indonesia, prevalensi beberapa indikator MetS pada tahun 2010 mengalami peningkatan dari tahun 2007, antara lain obesitas sentral dari 18,8\% menjadi 26,6\% dan hipertensi (diagnose oleh tenaga kesehatan berdasarkan wawancara) dari $7,6 \%$ menjadi $9,5 \%$. Sebesar 22,9\% penduduk Indonesia memiliki kadar HDL di bawah normal, dan $\quad 14,7 \%$ laki-laki serta $\quad 10,7 \%$ perempuan memiliki kadar trigliserida tinggi. Prevalensi diabetes terdiagnosis dokter atau gejala sebesar 2,1\% (Badan 
Penelitian dan Pengembangan Depkes

RI, 2013) Sementara, prevalensi sindrom metabolik sendiri dari hasil analisis data sekunder Riset Kesehatan Dasar 2007 sebesar 21,3\% pada perempuan dan 12,9\% pada laki-laki (Badan Penelitian dan Pengembangan Depkes RI, 2007). Salah satu propinsi di Indonesia dengan ancaman MetS adalah Daerah Istimewa Yogyakarta (DIY). Riskesdas 2013 menunjukkan bahwa prevalensi diabetes yang terdiagnosis dokter tertinggi terdapat di DIY $(2,6 \%)$, prevalensi hipertensi (diagnosis oleh nakes berdasarkan wawancara pada umur $\geq 18$ tahun) lebih dari 12\% (lebih tinggi dari prevalensi nasional), dan prevalensi obesitas sentral usia $\geq 15$ tahun_sebesar 27,3 \%juga melebihi angka nasional sebesar 26,6\% (Badan Penelitian dan Pengembangan Depkes RI, 2013)

Paparan informasi gizi mengenai pola makan yang baik dan diet gizi seimbang memiliki peranan penting dalam perilaku makan individu. Pengetahuan gizi yang kurang dapat menjadi penyebab pola hidup yang tidak sehat. Sebuah penelitian di Korea Selatan mengungkapkan bahwa pemberian edukasi gizi kepada subjek dengan sindrom metabolik, dapat memperbaiki pola makannya (Kim et al., 2013)

Riwayat keluarga yang mengalami penyakit degenerative seperti hipertensi/ diabetes/ jantung/ dislipidemia berperan dalam meningkatkan risiko penyakit degeneratif pada keturunannya. Sebuah penelitian menunjukkan bahwa anak dari orang tua dengan sindrom metabolik memiliki kadar HDLkolesterol dan apolipoprotein (apo E) yang lebih rendah dibandingkan dengan orang tua yang tidak mengalami sindrom metabolik ( matching pada jenis kelamin dan usia) (Maumus et al., 2005)

Hasil penelitian mengenai faktor-faktor risiko yang berkaitan dengan kejadian sindrom metabolik di Provinsi Daerah Istimewa Yogyakarta masih belum cukup banyak ditemukan. Oleh sebab itu, penelitian ini ingin mengetahui apa saja variabel yang berkaitan dengan kejadian sindrom metabolik dan faktor risikonya khususnya di Provinsi Daerah Istimewa Yogyakarta, dalam hal ini kemungkinan 
berkaitan dengan informasi gizi yang sehat, riwayat penyakit keluarga, dan jenis kelamin.

\section{METODE}

Penelitian ini dilaksanakan pada bulan Agustus - September 2018 dengan desain case control. Data yang telah diperoleh berasal dari pengunjung Puskesmas di 4 wilayah yang dipilih secara cluster random sampling dari Provinsi Daerah Istimewa Yogyakarta yaitu Puskesmas Kasihan 2 dan Jetis 2 mewakili Kabupaten Bantul, Puskesmas Pakualaman dan Tegalrejo mewakili Kotamadya Yogyakarta. Populasi adalah warga Provinsi Daerah Istimewa Yogyakarta, kemudian dipilih 2 kabupaten secara acak yaitu Kabupaten Bantul dan Kotamadya Yogyakarta, lalu dari masing-masing kabupaten dipilih 2 Puskesmas dengan data hipertensi tertinggi yaitu Puskesmas Jetis II dan Kasihan II (Kabupaten Bantul), Puskesmas Pakualaman dan Tegalrejo (Kotamadya Yogyakarta). Besar sampel adalah 81, yang terdiri dari 37 kasus dan 44 kontrol. Subjek dipilih menggunakan metode quota sampling. Subyek dipilih berdasarkan kriteria eksklusi dan inklusi menurut NCEP ATP III yaitu untuk kelompok kasus minimal mengalami 3 dari 5 kriteria sindrom metabolik, yaitu (1) obesitas sentral/abdomen (lingkar pinggang wanita $>88 \mathrm{~cm}$; laki-laki > $102 \mathrm{~cm}$ ); (2) kadar trigliserida darah $\geq$ $150 \mathrm{mg} / \mathrm{dl}$; (3) kadar kolesterol HDL $<40 \mathrm{mg} / \mathrm{dl}$ (wanita), $<50 \mathrm{mg} / \mathrm{dl}$ (pria); (4) tekanan darah $\geq 130 / 85 \mathrm{mmHg}$; (5) glukosa darah puasa $\geq 110 \mathrm{mg} / \mathrm{dl}$. Sedangkan untuk kelompok kontrol memenuhi kriteria normal.

Lingkar pinggang diukur lingkar terkecil bagian abdomen (sekitar dua jari di atas pusar) menggunakan metline. Lingkar pinggang diambil sebagai indikator obesitas sentral pada penelitian ini karena merupakan indikator terbaik dibandingkan dengan rasio lingkar pinggang panggul pada orang Asia (Ahmad et al., 2016). Tekanan darah diukur dengan menggunakan spignomanometer jarum, lingkar pinggang diukur menggunakan metline, dan kadar trigliserida diukur menggunakan alat hometest Multicare In. Data identitas umum meliputi jenis kelamin, usia, status merokok, dan tingkat pendidikan, penerimaan informasi gizi, dan riwayat penyakit 
keluarga diperoleh melalui kuesioner. Penerimaan informasi gizi dikatakan pernah jika pernah mendapatkan informasi tentang pengaturan makan dalam 6 bulan terakhir. Subjek dikatakan merokok jika dalam 30 hari terakhir merokok. Riwayat pendidikan dikategorikan berdasarkan pendidikan formal > 9 tahun yaitu level pendidikan terakhir SMA/sederajat ke atas, dan pendidikan formal $\leq 9$ tahun pada level SMP/sederajat kebawah (Pendidikan dasar) dengan berdasarkan Peraturan
Pemerintah No. 47 Tahun 2008 tentang Wajib Belajar. Riwayat penyakit keluarga dinilai dari ada keluarga inti (ayah/ibu/kakak/adik) yang mengalami minimal salah satu dari diabetes, hipertensi, obesitas, hiperlipidemia, hiperkolesterol. Data yang diperoleh diuji normalitas menggunakan uji Shapiro Wilk, kemudian data yang terdistribusi normal diuji statistik menggunakan chi-square test dan yang tidak terdistribusi normal diuji menggunakan fisher exact test.

\section{HASIL DAN PEMBAHASAN}

Tabel 1. Tekanan Darah, Lingkar pinggang dan Trigliserida Kelompok Kasus dan Kontrol

\begin{tabular}{lcccccccc}
\hline \multirow{2}{*}{ Variabel } & \multicolumn{2}{c}{ Mean \pm SD } & \multicolumn{2}{c}{ Median } & \multicolumn{2}{c}{ Minimum } & \multicolumn{2}{c}{ Maksimum } \\
\cline { 2 - 8 } & Kasus & Kontrol & Kasus & Kontrol & Kasus & Kontrol & Kasus & Kontrol \\
\hline Sistole & $144.3 \pm$ & $109.8 \pm$ & 140 & 110 & 110 & 80 & 250 & 130 \\
& 21.68 & 12.44 & & & & & & \\
Diastole & $89.38 \pm$ & $73.07 \pm$ & 90 & 73 & 70 & 55 & 100 & 90 \\
& 8.05 & 8.43 & & & & & & \\
Lingkar & 101.31 & $79.78 \pm$ & 97 & 110 & 88 & 63.7 & 175 & 100 \\
pinggang & \pm 14.58 & 7.96 & & & & & & \\
Trigliserida & 236.70 & $112.05 \pm$ & 221 & 112.5 & 151 & 49 & 395 & 151 \\
& \pm 63.55 & 23.31 & & & & & & \\
\hline
\end{tabular}

Tabel 2. Faktor Risiko Sindrom Metabolik

\begin{tabular}{|c|c|c|c|c|c|}
\hline Variabel & Kasus & Kontrol & OR & $\begin{array}{c}95 \% \\
\text { CI }\end{array}$ & p-value \\
\hline \multicolumn{6}{|l|}{ Jenis kelamin } \\
\hline Perempuan & $34(50.75 \%)$ & $33(49.5 \%)$ & 3,77 & & 0.0452 \\
\hline Laki-laki & $3(21.43 \%)$ & $11(78.57 \%)$ & & & \\
\hline \multicolumn{6}{|l|}{ Informasi Gizi } \\
\hline Belum Pernah & $17(20,99 \%)$ & $20(24,69 \%)$ & - & & 0.3293 \\
\hline Pernah & $25(30,86 \%)$ & $19(23.46 \%)$ & & & \\
\hline \multicolumn{6}{|l|}{ Aktivitas Fisik } \\
\hline Aktif & $6(54.55 \%)$ & $5(45.45 \%)$ & - & & 0.5254 \\
\hline
\end{tabular}




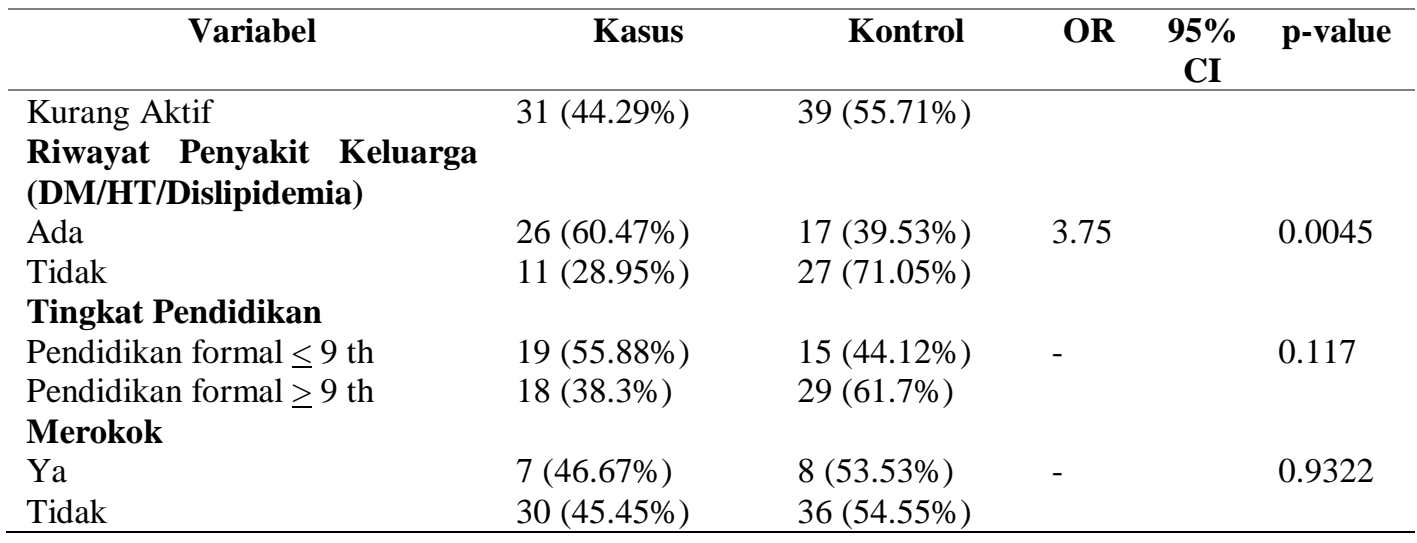

Tabel 3. Jumlah subjek yang memiliki riwayat penyakit degeneratif keluarga pada kelompok kasus dan kelompok kontrol

\begin{tabular}{lll}
\hline & Kasus & Kontrol \\
\hline Riwayat Penyakit Keluarga & $26(60.46 \%)$ & $17(39.54 \%)$ \\
Tidak Ada Riwayat Penyakit Keluarga & $11(28.95 \%)$ & $27(71.05 \%)$ \\
\hline
\end{tabular}

Tabel 4. Hubungan Keluarga dalam Riwayat Penyakit Keluarga Kelompok Kasus dan Kelompok Kontrol

\begin{tabular}{lcccc}
\hline \multicolumn{1}{c}{ Variabel } & $\begin{array}{c}\text { Kasus } \\
(\mathbf{n})\end{array}$ & $\begin{array}{c}\text { Persentase } \\
(\mathbf{\%})\end{array}$ & $\begin{array}{c}\text { Kontrol } \\
(\mathbf{n})\end{array}$ & $\begin{array}{c}\text { Persentase } \\
(\mathbf{\%})\end{array}$ \\
\hline Riwayat Penyakit Keluarga & & & & \\
Ayah & 10 & 38.46 & 5 & 29.41 \\
Ibu & 10 & 38.46 & 4 & 23.53 \\
Saudara Kandung & 1 & 3.85 & 1 & 5.88 \\
Kedua Orang Tua & 4 & 15.38 & 2 & 11.77 \\
Kedua Orangtua, Kakek, Nenek & 1 & 3.85 & 0 & 0 \\
Nenek & 0 & 0 & 1 & 5.88 \\
Paman & 0 & 0 & 2 & 11.77 \\
Bibi & 0 & 0 & 1 & 5.88 \\
Suami & 0 & 0 & 1 & 5.88 \\
\hline Jumlah & $\mathbf{2 6}$ & $\mathbf{1 0 0}$ & $\mathbf{1 7}$ & $\mathbf{1 0 0}$ \\
\hline
\end{tabular}

Sindrom metabolik merupakan sekumpulan gejala dari ketidaknormalan metabolisme dalam tubuh antara lain resistensi insulin, hiperglikemia, obesitas, dislipidemia aterogenik (kadar trigliserida > $150 \mathrm{mg} / \mathrm{dL}$; HDL rendah, LDL tinggi), dan hipertensi (Huang, 2009). Penelitian ini menunjukkan bahwa wanita memiliki risiko untuk mengalami sindrom metabolik 3,77 kali lebih besar dibandingkan laki-laki (OR= 3.77; p-value < 0,05). Hormon berperan penting dalam proses metabolisme tubuh baik pada wanita maupun pria. Namun pada wanita terutama pada usia menjelang menopause, hormon estrogen berkurang. Sebelum menopause, wanita memiliki risiko relatif lebih rendah 
mengalami penyakit kardiovaskuler aterogenik dibandingkan laki-laki. Estrogen menjadi faktor yang mempengaruhi kadar gula dan lipid dalam tubuh (Pradhan, 2014). Jika jumlah estrogen cukup, akan membantu dalam menjaga kadar gula darah dan lemak darah dalam kadar normal (Zainuddin et al., 2011)(Palmisano et al., 2018)

Riwayat penyakit keluarga yang mengalami penyakit degeneratif berhubungan signifikan dengan sindrom metabolik. Responden yang memiliki riwayat keluarga yang menderita penyakit degeneratif seperti diabetes, hipertensi, hiperkolsterol, dan atau disipidemia, memiliki risiko mengalami sindrom metabolik 3.75 kali lebih tinggi dibandingkan yang tidak memiliki riwayat penyakit di keluarga tersebut $(\mathrm{OR}=3.75 ; \mathrm{p}$ value $>0.05)$. Pada penelitian ini, dari 37 subjek kelompok kasus, 26 subjek (60.46\%) memiliki riwayat penyakit keluarga dan 11 subyek $(29.73 \%)$ tidak memiliki riwayat penyakit keluarga.dengan rincian $38.46 \%$ berasal dari ayah, $38.46 \%$ dari ibu, $15.38 \%$ dari kedua orang tua (ayah dan ibu), 3.85\% dari saudara kandung, dan $3.85 \%$ dari kedua orang tua serta nenek dan kakek mengalami penyakit degeneratif khususnya hipertensi, diabetes, dan atau obesitas. Sedangkan pada kelompok control, meskipun terdapat subjek yang memiliki riwayat penyakit keluarga, jumlahnya lebih sedikit dan hubungan kekeluargaan yang dimiliki tampak lebih jauh dibandingkan dengan kelompok kasus yaitu bibi, paman, suami. Seseorang dengan riwayat keluarga mengalami salah satu komponen MetS diindikasikan memiliki risiko yang lebih besar mengalami MetS dibandingkan dengan tidak memililiki riwayat keluarga. Sebuah studi populasi menunjukkan bahwa riwayat keluarga mengalami MetS menjadi tanda sebuah predisposisi genetik yang kuat untuk mengalami komplikasi kardiometabolik. Lebih dari $60 \%$ subjek dengan riwayat keluarga mengalami MetS, memiliki profil lipid yang abnormal (total kolesterol tinggi, kadar LDL tinggi, kadar HDL rendah, kadar trigliserida yang tinggi), dan subjek dengan riwayat keluarga mengalami MetS terindikasi mengalami resistensi insulin lebih tinggi di jaringan (Lipińska et al., 2014). 
Kejadian obesitas sentral berkaitan dengan riwayat keluarga yang mengalami kardiovaskuler, diabetes dan hipertensi pada semua partisipan penelitian di Ghana (Yeboah et al., 2017). MetS juga merupakan kontributor pada individu yang memiliki riwayat keluarga mengalami penyakit kardiovaskuler yang premature (Dallongeville et al., 2006). Individu yang memiliki riwayat keluarga mengalami diabetes melitus secara signifikan memiliki lingkar pinggang, rasio lingkar pinggang lingkar panggul, Indeks Massa tubuh, kadar glukosa darah puasa lebih besar dibandingkan dengan individu yang tidak memiliki riwayat Diabetes Melitus dikeluarganya (Das, Pal and Ghosh, 2012).

\section{Berdasarkan hasil penelitian} diperoleh data bahwa masih sedikit masyarakat yang mendapatkan informasi mengenai gizi terutama bagaimana pola makan yang sehat dan seimbang dan bagaimana supaya dapat mencegah penyakit degeneratif melalui pola makan yang baik (tabel 2). Pemberian konseling gizi secara langsung (face to face) selama tujuh kali terbukti dapat menurunkan nilai komponen MetS dan konseling menggunakan telepon selama tujuh sesi terbukti mampu memperbaiki pola makan subjek dengan MetS (Fappa et al., 2012) Di Malaysia, pengetahuan tentang diet pada subjek lanjut usia dengan kadar glukosa tinggi diungkapkan cukup kurang, begitu halnya dengan penelitian ini (Ju et al., 2010) Pada penelitian ini belum terbukti secara signifikan bahwa subjek yang pernah mendapatkan informasi gizi sebelumnya lebih rendah kejadian MetS, dikarenakan keterbatasan data yang diperoleh dari pertanyaan sudah pernah dan belum pernah saja. Kedepannya, perlu dilakukan penelitian spesifik mengenai bagaimana intervensi informasi gizi dapat memperbaiki pola makan penderita MetS dengan komponen pertanyaan yang lebih mendetail.

Tingkat pendidikan tidak berhubungan signifikan dengan kejadian sindrom metabolik ( $\mathrm{p}$ value >0,05). Berkebalikan dengan hasil penelitian di United States tahun 1988-2012 yang menyatakan rendahnya tingkat pendidikan memiliki risiko mengalami sindrom metabolik lebih besar (Moore, 
Chaudary and Aldnyemiju, 2017).

Kemungkinan dikarenakan perbedaan ukuran sampel dan desain penelitian, sehingga hasilnya masih belum konsisten.

Berdasarkan studi meta analisis, merokok aktif berkaitan erat dengan perkembangan sindrom metabolik (Sun, Liu and Ning, 2012) Namun pada penelitian ini merokok tidak berhubungan signifikan dengan sindrom metabolik. Hal ini dapat disebabkan karena proporsi perokok dalam responden penelitian ini cukup sedikit yaitu 7 orang pada kelompok kasus dan 8 orang pada kelompok kontrol.

\section{KESIMPULAN}

Sindrom metabolik berhubungan signifikan dengan riwayat adanya keluarga yang mengalami penyakit degeneratif (risiko meningkat 3.75 kali pada individu dari keluarga dengan riwayat penyakit denegeratif) metabolik dan jenis kelamin (risiko meningkat 3.77 kali pada wanita). Pernah dan tidaknya mendapatkan informasi gizi mengenai sindrom metabolik tidak berkaitan signifikan dengan kejadian sindrom metabolik pada penelitian ini.

\section{SARAN}

Perlu perhatian khusus untuk individu dari keluarga yang memiliki riwayat penyakit degeneratif terutama dalam hal informasi serta edukasi pola hidup yang sehat sehingga dapat mencegah dampak lebih lanjut penyakit degeneratif, diantaranya dengan deteksi dini sindrom metabolik. Penelitian ini memiliki keterbatasan sampling dan lokasi penelitian, sehingga diharapkan penelitian selanjutnya mampu dilaksanakan dengan sampel yang lebih besar, metode random sampling dan dengan cakupan wilayah kabupaten yang lebih luas, supaya lebih representatif.

\section{UCAPAN TERIMA KASIH}

Kami ucapkan terima kasih kepada Kementerian Riset dan Teknologi Pendidikan Tinggi yang telah membantu mendanai penelitian ini dengan bentuk Hibah Penelitian Dosen Pemula, Universitas Aisyiyah Yogyakarta yang telah mendukung kelancaran penelitian, enumerator, responden, dan Puskesmas di wilayah Kabupaten Bantul dan Kotamadya Yogyakarta 


\section{DAFTAR PUSTAKA}

Ahmad, N., Ibrahim, S., Adam, M., Nawi, A. M., \& Hassan, M. R. (2016). Abdominal Obesity Indicators: Waist Circumference or Waist-to-hip Ratio in Malaysian Adults Population. International Journal of Preventive Medicine, 7, 82.

Badan Penelitian dan Pengembangan Depkes RI. (2007). Riset Kesehatan Dasar Departemen Kesehatan Republik Indonesia. Riskesdas. https://doi.org/1 Desember 2013

Badan Penelitian dan Pengembangan Depkes RI. (2013). Riset Kesehatan Dasar Departemen Kesehatan Republik Indonesia. Riset Kesehatan Dasar Departemen Kesehatan Republik Indonesia. https://doi.org/10.1007/s13398014-0173-7.2

Dallongeville, J., Grupposo, M. C., Cottel, D., Ferrières, J., Arveiler, D., Bingham, A., ... Amouyel, P. (2006). Association between the metabolic syndrome and parental history of premature cardiovascular disease. European Heart Journal, 27(6), 722-728.

https://doi.org/10.1093/eurheartj/ehi717

Das, M., Pal, S., \& Ghosh, A. (2012). Family history of type 2 diabetes and prevalence of metabolic syndrome in adult Asian Indians. Journal of Cardiovascular Disease, $\quad 3(2), \quad 1-5$. https://doi.org/10.4103/0975-3583.95362

Fappa, E., Yannakoulia, M., Ioannidou, M., Skoumas, Y., Pitsavos, C., \& Stefanadis, C. (2012). Telephone counseling intervention improves dietary habits and metabolic parameters of patients with the metabolic syndrome: A randomized controlled trial. Review of Diabetic Studies, $\quad 9(1), \quad 36-45$. https://doi.org/10.1900/RDS.2012.9.36

Grundy, S. M., Brewer, H. B., Cleeman, J. I., Smith, S. C., \& Lenfant, C. (2004). Definition of Metabolic Syndrome Report of the National Heart, Lung, and Blood Institute/American Heart Association Conference on Scientific Issues Related to Definition. Circulation, 109(3), 433-438. https://doi.org/10.1161/01.CIR.000011124 5.75752.C6

Hadaegh, F., Zabetian, A., Tohidi, M., Ghasemi, A., Sheikholeslami, F., \& Azizi, F. (2009).
Prevalence of metabolic syndrome by the Adult Treatment Panel III, International Diabetes Federation, and World Health Organization Definitions and their association with coronary heart disease in an elderly Iranian population. Annals of the Academy of Medicine Singapore, $38(2), 142-149$.

Huang, P. L. (2009). A comprehensive definition for metabolic syndrome. Disease Models \& Mechanisms, 2(5-6), 231-237. https://doi.org/10.1242/dmm.001180

Ju, L., Shahar, S., Yahya, H., Ching, T., Nor, L., Chuo, L., ... Mukhsan, N. (2010). Tahap Pengetahuan Pemakanan dan Kesedaran Kesihatan di Kalangan Pesakit. Sains Malaysiana, 39(3), 505-511.

Kim, J., Bea, W., Lee, K., Han, J., Kim, S., Kim, M., ... Sohn, C. (2013). Effect of the telephone-delivered nutrition education on dietary intake and biochemical parameters in subjects with metabolic syndrome. Clinical Nutrition Research, 2, 115-124. https://doi.org/10.7762/cnr.2013.2.2.115

Lipińska, A., Koczaj-Bremer, M., Jankowski, K., Kaźmierczak, A., Ciurzyński, M., OuPokrzewińska, A., ... Pruszczyk, P. (2014). Does family history of metabolic syndrome affect the metabolic profile phenotype in young healthy individuals? Diabetology and Metabolic Syndrome, 6(1), 1-6. https://doi.org/10.1186/17585996-6-75

Maumus, S., Marie, B., Gerard, S., \& VisvikisSiest, S. (2005). A Prospective Study on the Prevalence of Metabolic Syndrome Among Healthy French Families. Diabetes Care, 28(3), 675-682.

Moore, J. X., Chaudary, N., \& Aldnyemiju, T. (2017). Metabolic Syndrome Prevalence by Race/ Ethnicity and Sex in the United States, National Health and Nutrition Examination Survey, 1988-2012. Preventing Chronic Disease, 14(E24), 1$16 . \quad$ https://doi.org/10.1016/S00260576(13)70219-8

Nelson, R. H. (2014). Hyperlipidemia as a Risk Factor for Cardiovascular Disease, 40(1), 195-211. https://doi.org/10.1016/j.pop.2012.11.003. Hyperlipidemia

Palmisano, B. T., Zhu, L., Eckel, R. H., \& 
Stafford, J. M. (2018). Sex differences in lipid and lipoprotein metabolism. Molecular Metabolism, 15, 45-55. https://doi.org/10.1016/j.molmet.2018.05. 008

Parikh, R., \& Mohan, V. (2012). Changing definitions of metabolic syndrome. Indian Journal of Endocrinology and Metabolism, 16(1), 7. https://doi.org/10.4103/2230-8210.91175

Pradhan, A. D. (2014). Sex differences in the metabolic syndrome: Implications for cardiovascular health in women. Clinical Chemistry, 60(1), 44-52. https://doi.org/10.1373/clinchem.2013.202 549

Sun, K., Liu, J., \& Ning, G. (2012). Active Smoking and Risk of Metabolic Syndrome: A Meta-Analysis of
Prospective Studies. PLoS ONE, 7(10). https://doi.org/10.1371/journal.pone.0047 791

Yeboah, K., Dodam, K. K., Affrim, P. K., AduGyamfi, L., Bado, A. R., Owusu Mensah, R. N. A., ... Gyan, B. (2017). Metabolic syndrome and parental history of cardiovascular disease in young adults in urban Ghana. BMC Public Health, 18(1), 1-8. https://doi.org/10.1186/s12889-0174652-6

Zainuddin, L. R. M., Isa, N. F., Wan Muda, W. M., \& Mohamed, H. J. (2011). The prevalence of metabolic syndrome according to various definitions and hypertriglyceridemic-waist in Malaysian adults. International Journal of Preventive Medicine, 2(4), 229-237. 